\title{
Hydrolysis of casein: a differential aid for the indentification of Serratia marcescens
}

\author{
WILLIAM A. SALISBURY AND JOSEPH J. LIKOS \\ From the Veterans Administration Hospital, Phoenix, Arizona, USA
}

SYNOPSIS Through the hydrolysis of casein, a cultural characteristic has been established in the preliminary identification of Serratia marcescens. Compared against 438 strains of the families, Pseudomonadaceae and Enterobacteriaceae, this organism has a reproducible capability to decompose casein, while most other Gram-negative bacilli failed to produce any hydrolysis, or, at the most, hazy zones only. Routine use has shown this to be a valuable differential aid in the identification of Serratia marcescens.

The separation and identification of the Gramnegative bacteria within the genera Pseudomonas, Aeromonas, Serratia, and Proteus in a busy hospital microbiology laboratory can be a difficult and timeconsuming chore. Many methods have been described to assist in the separation and identification of this group of bacteria. We should like to add an observation which has proved quite successful in the isolation of the nonpigmented strains of Serratia marcescens (Clayton and von Graevenitz, 1966; Wilfert, Barrett, Ewing, Finland, and Kass, 1970). This organism has demonstrated an easily recognizable and reproducible capability to hydrolyze casein in a defatted milk medium.

Serratia marcescens has become a significant organism (Davis, Foltz, and Blakemore, 1970; Sanders, Luby, Johanson, Barnett, and Sanford, 1970; Black, Hodgson, and McKechnie, 1971) in our nosocomial infections and hospital epidemiology. Utilizing the work of Brown and Scott Foster (1970), we have been using a defatted milk agar (Hasting, 1903; Gordon and Smith, 1955; Ajello et al, 1963) in our routine as a diagnostic aid in the identification of Pseudomonas aeruginosa by its hydrolysis of casein and pigmentation. Preliminary examination of these milk agar plates reveals a nonpigmented colony with a recognizable zone of hydrolysis that is distinctly different than Pseudomonas and is confirmed to be Serratia marcescens by its characteristic DNase production (Elston and Elston, 1968; Black et al, 1971) decarboxylase activity (Ewing, Davis, and Edwards, 1960), sensitivity profiling (Bauer, Kirby, Sherris, and Turck, 1966), and colony characteristics on other Received for publication 3 October 1972. media. This reproducible colony characteristic has successfully withstood comparison against 438 strains of the families, Enterobacteriaceae and Pseudomonadaceae. Our study, as listed in Table I, has demonstrated that three bacterial species of the above families produce hydrolysis of milk protein as follows: Serratia marcescens (97\%), Pseudomonas aeruginosa (99\%), and Proteus mirabilis (94\%).

\section{Materials and Methods}

The selection of a single and inexpensive milk agar is one that a laboratory of any size could utilize in their bacteriological screening. Gordon and Smith (1955) and Ajello, Georg, Kaplan, and Kaufman (1963) used the following casein medium in the separation of Nocardia and Streptomyces species. We have incorporated this medium in our procedure.

CASEIN Medium (AJello et al, 1963 ;

HASTINGS, 1903)

Prepare separately:

1 Skim milk (dehydrated or instant non$\begin{array}{llllll}\text { fat milk) } & \ldots & \ldots & \ldots & \ldots & 10 \mathrm{~g}\end{array}$ Distilled water $\quad . \quad \ldots \quad \ldots \quad \ldots \quad \ldots 100 \mathrm{ml}$

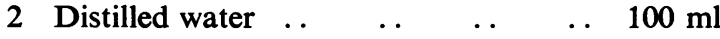
$\begin{array}{lllllll}\text { Agar } & \ldots & \ldots & \ldots & \ldots & \ldots & 2 \mathrm{~g}\end{array}$

Autoclave at $120^{\circ} \mathrm{C}$ for 20 minutes. Cool both solutions to about $45^{\circ} \mathrm{C}$. Mix and pour into sterile petri dishes.

All organisms were seeded on the skim milk agar by point inoculation. For screening procedures, six to eight isolates may be cultured on each plate. The cultures were incubated for 24 hours at 35 to $37^{\circ} \mathrm{C}$ 

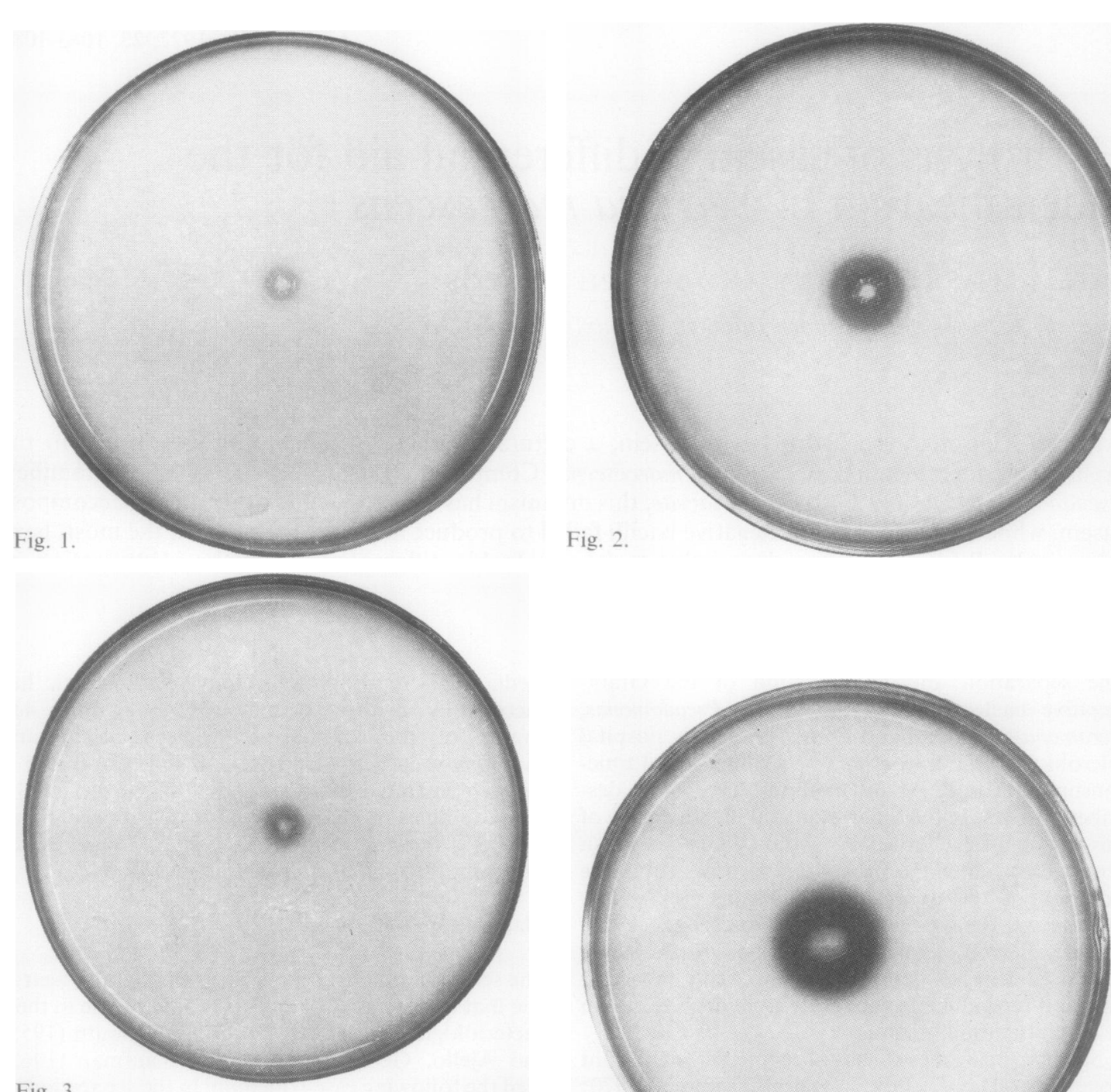

Fig. 3.

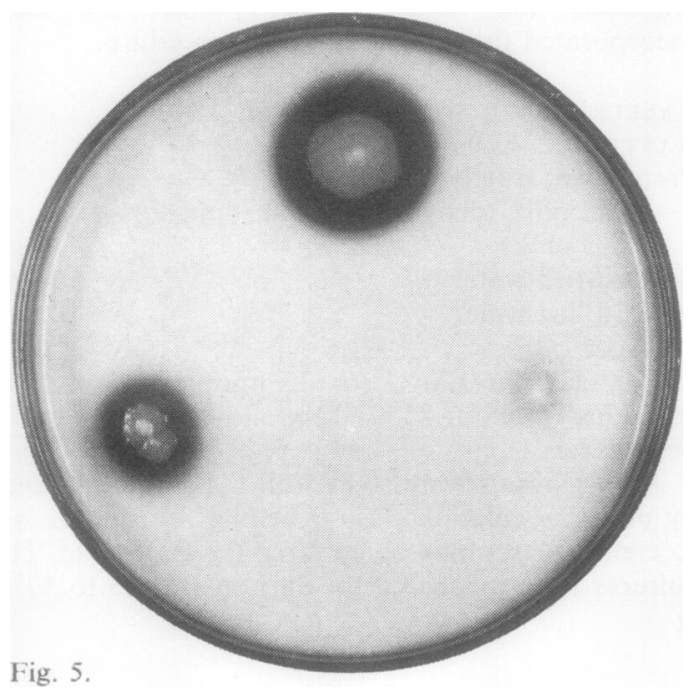

ig. 2

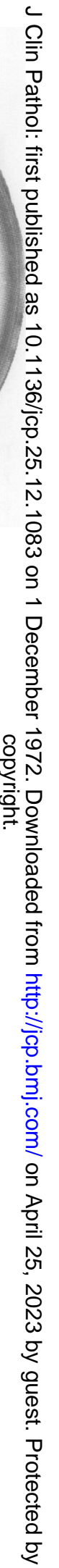




\begin{tabular}{|c|c|c|c|c|}
\hline Organism & No. Tested & $\begin{array}{l}24-\mathrm{Hr} \text { Reading at } \\
35-37^{\circ} \mathrm{C} \\
\text { Average diameter of } \\
\text { clear zone }(a) \\
\text { (millimetres) }\end{array}$ & $\begin{array}{l}\text { 48-Hr Reading at } \\
\text { Room Temperature } \\
\text { Average diameter of } \\
\text { blear zone }(a) \\
\text { (millimetres) }\end{array}$ & Remarks \\
\hline Alk. faecalis & 10 & 0 & 0 & Two appeared with hazy zones \\
\hline Citrobacter-Esch.Gr. & 3 & 0 & 0 & - \\
\hline Ent. aerogenes & 19 & 0 & $\mathbf{0}$ & - \\
\hline Ent. cloacae & 14 & $\mathbf{0}$ & $3(\mathrm{SH})$ & Hazy zone only \\
\hline Ent. hafnia & 8 & 0 & 3(SH) & Hazy zone only \\
\hline Ent. liquifaciens & 2 & 0 & 0 & - \\
\hline Esch. coli & 58 & 0 & $\mathbf{0}$ & - \\
\hline Herellea vaginicola & 16 & 0 & 0 & 一 \\
\hline Klebsiella pneumoniac & 49 & 0 & $\mathbf{0}$ & - \\
\hline Proteus mirabilis & 53 & $2(\mathrm{SH})^{1}$ & $4(\mathrm{SH})$ & Three produced no clearing \\
\hline Proteus morganii & 8 & 0 & 0 & - \\
\hline Proteus rettgeri & 13 & 0 & $\mathbf{0}$ & - \\
\hline Proteus vulgaris & 6 & $3(\mathrm{SH})$ & $6(R H)$ & Two produced only hazy zones \\
\hline Providence alcalifaciens & 2 & 0 & 0 & - \\
\hline Pseudomonas aeruginosa & 99 & $6(\mathrm{RH})^{2}$ & 13(RH) & One produced no clearing \\
\hline Salmonella, group $A$ & 2 & 0 & 0 & - \\
\hline Serratia marcescens & 74 & S(RH) & $12(\mathrm{RH})$ & Two produced no clearing \\
\hline Shigella-sonnei, subgroup $D$ & 2 & 0 & 0 & - \\
\hline
\end{tabular}

Table I Results of casein hydrolysis among members of the families Enterobacteriaceae and Pseudomonadaceae

${ }^{1} \mathrm{SH}=$ slow hydrolysis, $\quad{ }^{2} \mathrm{RH}=$ rapid hydrolysis

and then examined for evidence of casein hydrolysis. Plates were left at room temperature for another 24 hours, when the second inspection was made. Figures 1, 2, 3, 4, and 5 show typical examples. Cultures were not incubated at 35 to $37^{\circ} \mathrm{C}$ for the entire 48 hours because of the rapid spreading and overgrowth of a number of the isolates.

\section{Discussion}

Table I shows the comparison between different members of the families, Enterobacteriaceae and Pseudomonadaceae, presenting their ability to decompose casein in a short period of time. Routine use has proven valuable in confirming the presence of Pseudomonas aeruginosa and Serratia marcescens with clear transparent zones while most other organisms failed to produce any hydrolysis or at the most, hazy zones only. Few aberrant results were obtained in the bacterial strains isolated. We conclude from this study that the hydrolysis of casein is a valuable differential aid in the identification of Serratia marcescens.

The authors wish to express their thanks to Charles Dillman for his technical assistance and to Mr D. E. Deuel for preparation of the photographic material.
References

Ajello, L., Georg, L. K., Kaplan, W., and Kaufman, L. (1963). Laboratory Manual for Medical Mycology (Public Health Service Publication, no. 994). Communicable Disea ses Center, Atlanta, Georgia.

Bauer, A. W., Kirby, W. M. M., Sherris, J. C., and Turck, M. (1966). Antibiotic susceptibility testing by a standardized single disk method. Amer. J. clin. Path., 45, 493-496.

Black, W. A., Hodgson, R., and McKechnie, A. (1971). Evaluation of three methods using deoxyribonuclease production as a screening test for Serratia marcescens. J. clin. Path., 24 313-316.

Brown, M. R. W., and Scott Foster, J. H. (1970). A simple diagnostic milk medium for Pseudomonas aeruginosa. J. clin. Path., 23, 172-177.

Clayton, E., and von Graevenitz, A. (1966). Nonpigmented Serratia marcescens. J. Amer. med. Ass., 197, 1059-1064.

Davis, J. T., Foltz, E., and Blakemore, W. S., MD's. (1970). Serratia marcescens. J. Amer. med. Ass., 214, $2190-2192$.

Elston, H. R., and Elston, J. H. (1968). Further use of deoxyribonuclease in a screening test for Serratia. J. clin. Path., 21, 210-212.

Ewing, W. H., Davis, B. R., and Edwards, P. R.(1960). The decarboxylase reaction of Enterobacteriaceae and their value in taxonomy. Publ. Hlth. Lab., 18, 77-83.

Gordon, R. E., and Smith, M. M.(1955). Prepared group of characters for the separation of Streptomyces and Nocardia. J. Bact., 69, 147-150.

Hastings, E. G. (1903). Milkagar as a medium for demonstrating the production of proteolytic enzymes. Science, 17, 372.

Sanders, C. V., Jr., Luby, J. P., Johanson, W. G. Jr., Barnett, J. A., and Sanford, J. P. (1970). Serratia marcescens infections from inhalation therapy medications: Nosocomial outbreak. Ann. intern. Med., 73, 15-21.

Wilfert, J. N., Barrett, F. F., Ewing, W. H., Finland, M., and Kass, E. H. (1970). Serratia marcescens: biochemical, serological, and epidemiological characteristics and antibiotic susceptibility of strains isolated at Boston City Hospital. Appl. Microhiol., 19, 345-352. 